\title{
Special issue devoted to papers presented at the first international conference on information systems technology and management, New Delhi, March 12-13, 2007
}

\author{
Kamna Malik · Anurag Agarwal
}

Published online: 24 February 2009

(C) Springer Science+Business Media, LLC 2009

The First International Conference on Information Systems Technology and Management was held in New Delhi in March, 2007. The conference was organized jointly by the University of Florida, USA and the Institute of Management and Technology, Ghaziabad, India. Forty-seven papers, divided into three tracks, were presented at the conference. The tracks were: Information Systems, Information Technology and Information Management. For this special issue, devoted to ICISTM-07, nine papers were submitted for consideration, of which two have been accepted for publication.

The first paper, titled, 'Reactivity Based Model to Study Online Auctions Dynamics,' by Pereira et al. addresses bidder behavior issues in online auction environments. The paper develops a new characterization model for online auctions. In this model, they take into account the change in a bidder's behavior motivated by events during the course of an auction. The new model is applied to actual datasets of eBay auctions to understand specific online auction negotiation patterns. The model has implications for the design of more complete automatic agents.

The second paper titled 'Computing Full Disjunction Using COJO' by Kumar et al. addresses the issue of data integration in a relational database management environment. The authors propose a 'Correct Outer Join Ordering' strategy which results in full disjunction of relations resulting in a better database design compared to existing strategies.

K. Malik $(\square)$

U21Global, New Delhi, India

e-mail: kamna.malik@u21global.edu.sg

A. Agarwal

University of Florida, Gainesville, USA

e-mail: aagarwal@ufl.edu 